Kurt Mendgen, Klaus Welter, Frank Scheffold and

Gertrude KnaUf-Beiter

\title{
High Pressure Freezing of Rust Infected Plant Leaves
}

\section{Introduction}

Chemical fixation of plant leaves is a relatively slow process. Penetration of glutaraldehyde or osmic acid may extend over many minutes. In terms of cellular processes, this is a very long time, resulting in the introduction of numerous artifacts, such as undulation of membranes [23,19]. This problem is even more pronounced in plants infected by pathogens. The hyphae or reproductive structures of fungal pathogens in plant tissue are variable in their structure and composition. The penetration of such cells by fixatives may be affected by the thickness or composition of their walls. For instance, the host-parasite interface of rust haustoria within plant cells appears quite distorted after chemical fixation [e.g. 18].

Rapid cryofixation is recommended as an alternative to chemical fixation [31, $28,29,6,32,37]$. In plant pathology such methods have successfully been applied to infected epidermal cells [10,5], fungal hyphae [12,11, Hoch Chap. 1, this Vol) or fungal spores [24]. In samples of larger size, however, artificial segregation compartments destroy the tissue during freezing at ambient pressure. Slow heat transfer in biological tissue restricts the application of such methods to samples with a thickness of a few microns [33]. The depth of a well-preserved border zone in the tissue can be increased by applying pressure of at least 2000 bar before freezing is performed [27,25]. With high pressure freezing (hpf) as introduced by Moor [25], complete root tips were frozen adequately $[4,14]$. However, plant leaves have still proven difficult to freeze uniformly. The intercellular spaces are filled with air and in fungal infected tissues the intercellular mycelium may also trap small air spaces. Therefore, such leaves were previously infiltrated with water to avoid pressureinduced damage $[15,35]$. However, only small areas were well preserved in most samples. Heat transfer appeared to be very uneven in such highly vacuolated tissue. To improve the situation, we studied rust-infected leaves of different host plants infiltrated with different concentrations of methanol, as described by Welter et al. [35], or hexadecene, as described by Studer et al. [34]. The experiments with samples

Lehrstuhl für Phytopathologie, Fakultät für Biologie, Universität Konstanz, Post Fach 5560, D-7750 Konstanz, FRG 
Table 1. Variations of experiments performed to obtain optimal conditions for cryopreservation of rust infected plant tissues for ultrastructural study

No. of

Experiment

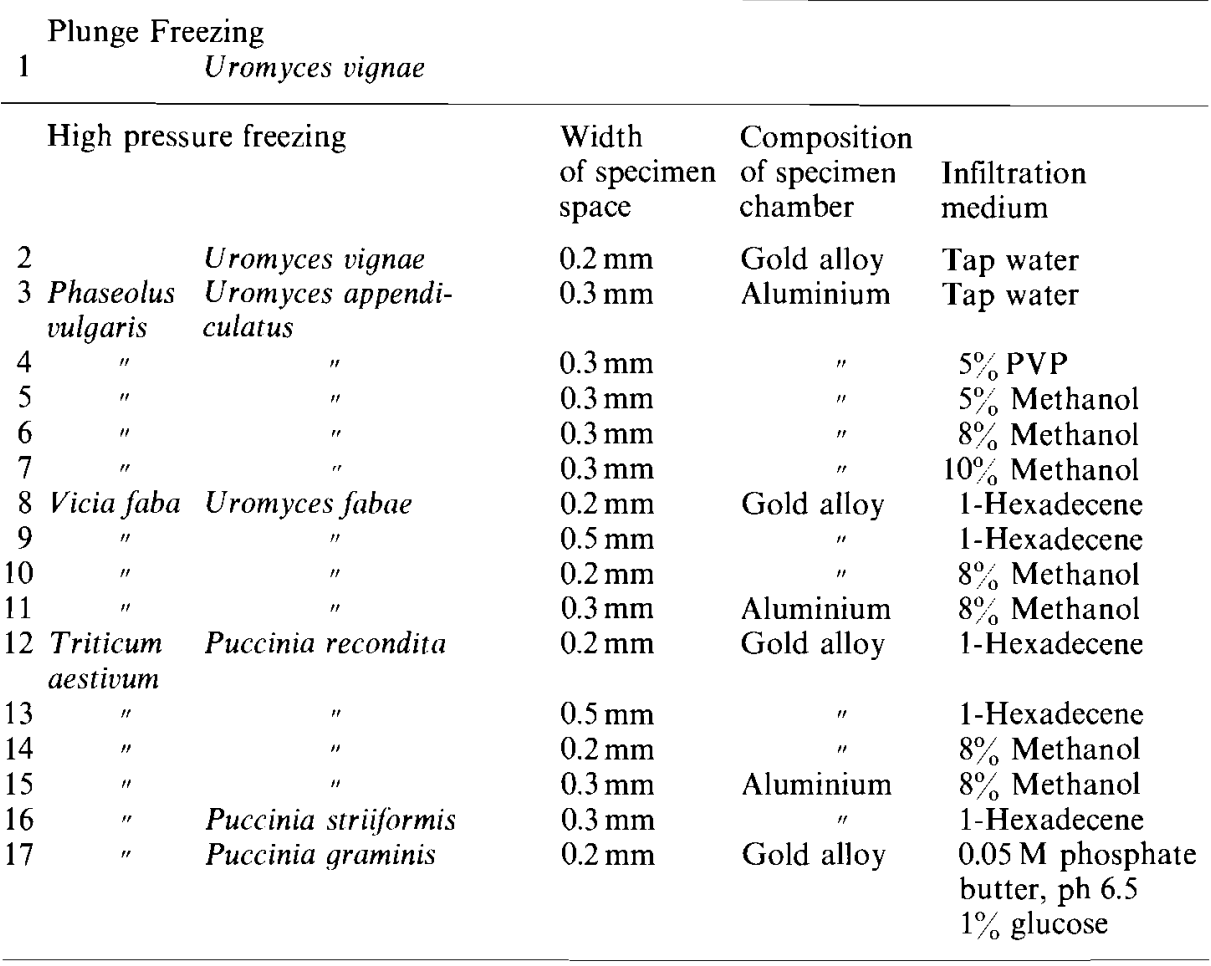

that were freeze substituted are listed in Table 1 . Some results after hpf and freeze fracturing [15] are shown in addition. For comparison, infection hyphae of Uromyces vignae grown on membranes were plunge frozen and, after freeze substitution, processed similarly to the rust-infected leaves.

\section{The Specimen Sandwich}

A cross-section of the sandwiches used to enclose the leaf samples is shown in Fig. 1. They are simpler than those recommended by Craig et al. [3] and thinner than those suggested by Moor [25]. The platelets were made either of an alloy of $95 \%$ gold and $5 \%$ nickel or of aluminum. We found no differences in the preservation of fine structure using either gold platelets with $0.2 \mathrm{~mm}$ space (Table 1, Exp. 8, 10,12,14) or aluminum platelets with $0.3 \mathrm{~mm}$ space (Table 1, Exp. 11,15). However, gold platelets with $0.5 \mathrm{~mm}$ space (Table 1, Exp. 9,13) gave inferior results, with many segregation compartments occurring throughout the specimen. 

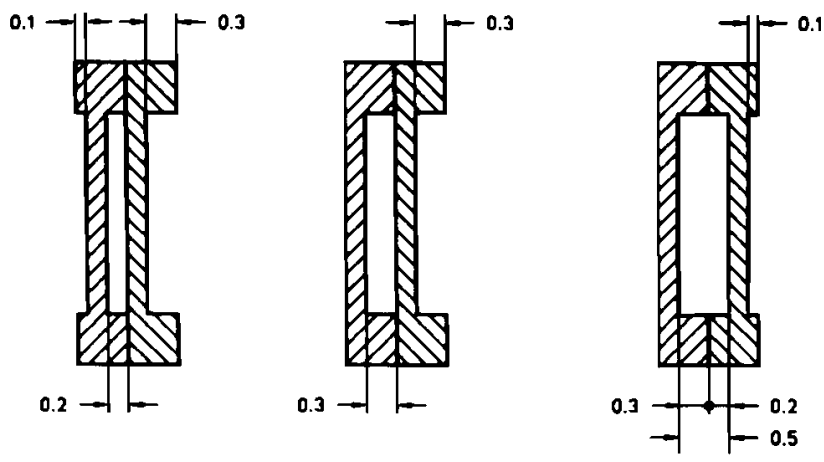

Fig. 1. Cross-sections through specimen chambers used for hpf of plant leaf tissue. The width of the specimen space is $0.2,0.3$ or $0.5 \mathrm{~mm}$, the total thickness of the specimen chamber is $1 \mathrm{~mm}$

\section{Plunge Freezing vs. High Pressure Freezing}

The reduced cooling rate compared to plunge freezing and the application of high pressure before freezing starts gave rise to concerns of possible damage to tissue caused by $h$ pf $[25,32]$. Similar to the results obtained by a prototype [25], our commercial instrument reaches a pressure of 2100 bar within $18 \pm 0.5 \mathrm{~ms}$. The pressure is maintained for $520 \pm 15 \mathrm{~ms}$. If the sample in the sandwich is replaced by a thermocouple, the drop in temperature, which begins at 2100 bar, takes $9.5 \pm 0.4 \mathrm{~ms}$ to decrease from $273 \mathrm{~K}$ to $223 \mathrm{~K}$. Since it can be assumed that the conditions in the thermocouple differ from those in a plant leaf [17], we do not know very much about the time course of the temperature in our samples. To obtain a rough estimate on the influence of hpf on the rust fine structure, we compared the results of the following experiments:

$U$. vignae $(=U$. phaseoli var. vignae) infection hyphae [21] were grown on scratched polyethylene sheets, plunge frozen as described by Howard and O'Donnell [13], freeze substituted and further processed as described by Welter et al. [35] (Table 1, Exp. 1). U. vignae infection hyphae raised as above were covered with water and, after hpf, (Table 1, Exp. 2) processed as above. Puccinia graminis f. sp. tritici sporogenous hyphae growing below the wheat leaf epidermis were, after infiltration, high pressure frozen and processed as above (Table 1, Exp. 17).

To compare results after freeze-substitution and freeze-fracturing, $U$. appendiculatus ( $=U$. phaseoli var. phaseoli) sporogenous hyphae growing below the epidermis of a bean leaf were, after water infiltration, high pressure frozen and freeze fractured as described by Knauf and Mendgen [15].

The cytoplasm of the infection hyphae of $U$. vignae exhibited a comparable fine structure after plunge-freezing and hpf. The membranes of mitochondria and endoplasmatic reticulum were smooth and parallel (Fig. 2a,b). Also in the sporogenous hyphae of $P$. graminis, the mitochondria (Fig. 2c) looked very similar 


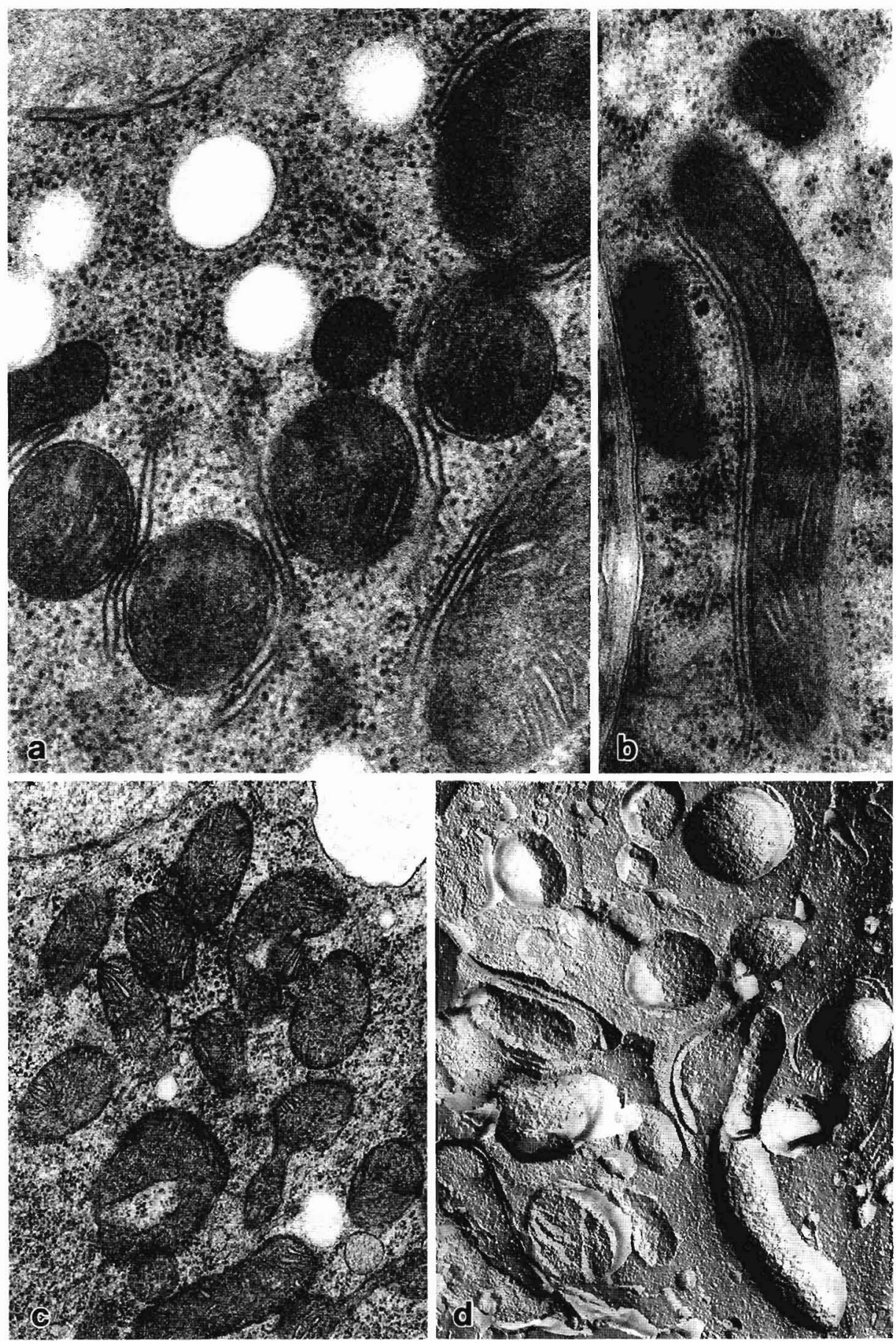




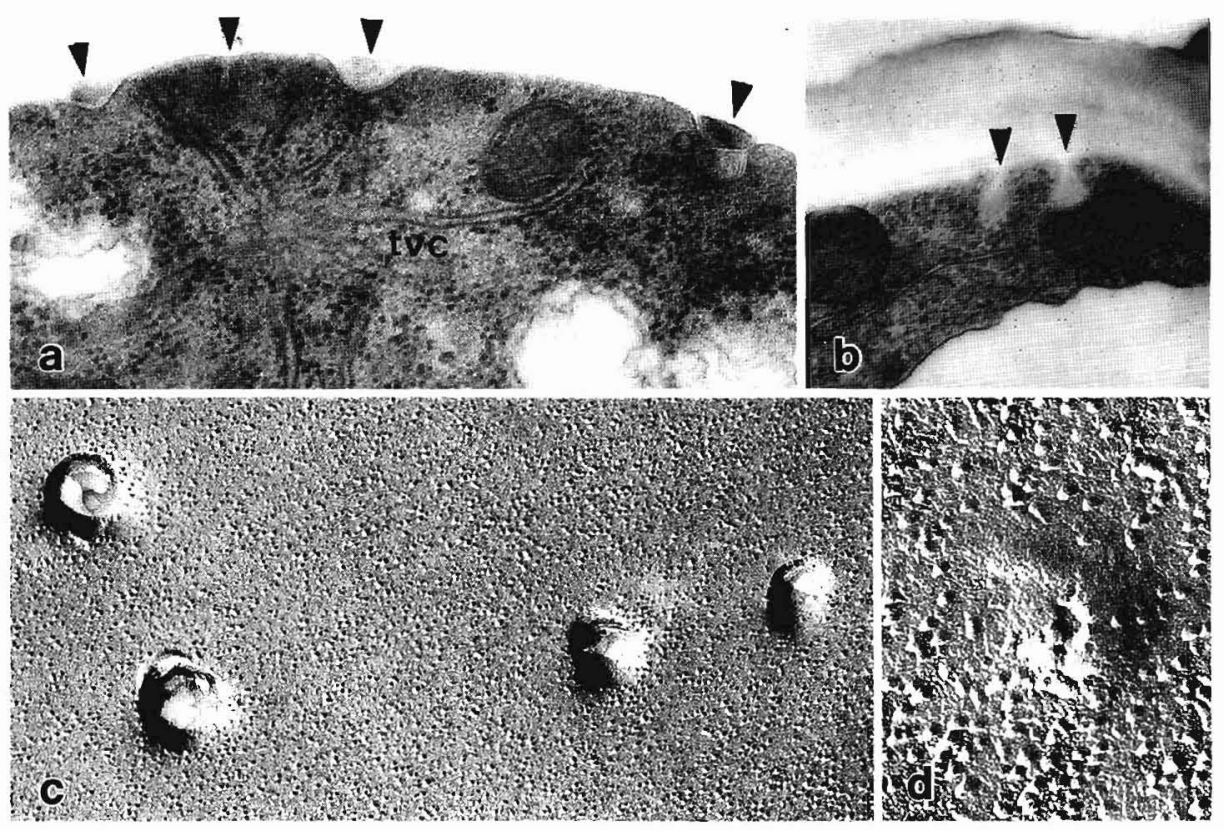

Fig. 3. Structures related to exo-endocytotic processes in hyphae of different rust fungi; a plunge freezing and freeze substitution of $U$. vignae infection hyphae; arrow heads secretion profile; tvc tubular vesicular complex (see 35 ), $\times 40000 . \mathbf{b}$ hpf and freeze substitution of $P$. striiformis sporogenous hyphae; arrow heads secretion profile, $\times 20000$. ch hp and freeze fracturing of $U$. appendiculatus sporogenous cells, protoplasmic face, with various depressions, which may correspond to the depressions indicated in the cross-sections of a, $\times 52000$. d hpf and freeze fracturing of $U$. appendiculatus sporogenous cells, protoplasmic face, with sectory opening, $\times 103000 . \mathbf{d}$ from [15]

to those of $U$. vignae in Fig. $2 \mathrm{a}$ and b. After hpf and freeze fracturing sporogenous tissue of $U$. appendiculatus (Fig. 2d) exhibited similar profils of ER and mitochondria. Obviously, the results of the different techniques are comparable, with the reservation that different, although related, rust fungi were used.

In addition, membrane profiles suggesting exo-endocytotic processes have been observed in infection hyphae after plunge freezing and freeze substitution (Fig. 3a), in sporogenous hyphae after high pressure freezing and freeze substitution (Fig. 3b) and in sporogenous hyphae after hpf and freeze fracturing (Fig. 3c, d). Possible secretory openings were observed after hpf (Fig. 3d).

From our results, it appears that the high pressure had no adverse affects on membrane structure, since their profiles were similar after plunge freezing or hpf. It seems that hpf is sufficiently rapid to immobilize cellular processes such as exo-

Fig. 2. The cytoplasm in the infection hyphae of Uromyces vignae after a hpf, $\times 42000$, and b plunge freezing, $\times 44000$, followed by freeze substitution. The cytoplasm of Puccinia graminis sporogenous hyphae $\mathrm{c}$ after hpf and freeze substitution, $\times 25000$, and the sporogenous hyphae of d Uromyces appendiculatus after hpf and freeze fracturing, $\times 20250$ 
endocytosis, especially at the specimen surface, where the sporogenous hyphae are located. Similar results were obtained with pituitary cells (36). We do, however, not exclude the possibility of adverse pressure effects such as on membrane lipids (20) that are not apparent with our methods. Also, very rapid events such as may occur at the contact point of fusing membranes [17] may still not be immobilized by these methods.

\section{Infiltration of Leaves}

Infiltration of leaves was obtained under the mild vacuum of a water jet pump. During infiltration with the different media (Table 1), we checked with a microscope that no gas bubbles remained in the tissue. Leaf discs were cut out with a steel cork borer, placed between the platelets of the specimen chamber (Fig. 1, Table 1) and introduced into the instrument for hpf. The whole procedure was performed within $8 \mathrm{~min}$. Processing followed as described elsewhere [35]. From the samples, $2 \mu \mathrm{m}$ thick sections, about $1.5 \times 0.2 \mathrm{~mm}$ large, were cut with glass knives and evaluated with phase contrast optics. Areas with minimal detectable structural damage were then selected for further study with the electron microscope.

After infiltration of bean leaves with water (Table 1, Exp. 3) or wheat leaves with buffer (Table 1, Exp. 17) serious damage, probably as a result of ice crystal formation, was ovious throughout the leaf parenchyma. Less than $10 \%$ of the mesophyll cells remained intact. In these few cells, haustoria exhibited a wellpreserved fine structure. In the bundles, many phloem parenchyma cells remained intact (Fig. 4a). The cytoplasm in some intercellular hyphae was well preserved. Good results were obtained with all the hyphae of the sporogenous tissue. No ice crystal damage was evident in these hyphae except for very small areas in the nucleus (Fig. 2c). Infiltration of bean plants with $5 \%$ polyvinylpyrrolidone (PVP) did not improve the results significantly (Table 1, Exp. 4).

Infiltration with 5,8 or $10 \%$ methanol in water (Exp. 5,6,7) as a cryoprotectant dramatically improved tissue preservation. After the application of $5 \%$ methanol some highly vacuolated cells were still damaged. Ten percent methanol induced shrinkage of some cells of the leaf parenchyma and also of some hyphae (Fig. 4b). With $8 \%$ methanol, good results were obtained throughout the leaf tissue including all fungal structures $[35,16]$. These improved results using methanol were obtained with bean rust (U. appendiculatus) in beans (Exp. 6), broad bean rust

Fig. 4. Variations of pretreatment and consecutive processing of material after hpf. a Phloem parenchyma of bean ( $P$ h. vulgaris), water infiltrated, $\times 14700$. b Bean leaf, $10 \%$ methanol infiltrated, $\times 2800$. c Haustorium of $P$. striiformis in wheat $(T$. aestivum), 1-hexadecene infiltrated, $\times 17000$. d Wheat parenchyma, 1-hexadecene infiltrated, $\times 17150$. $P$. striformis, sporogenous cell, Lowicryl K $11 \mathrm{M}$ embedded, $\times 11150$. $\mathrm{U}$. phaseoli, freeze etch replica of the haustorial host-parasite interface; eme extrahaustorial membrane; fpm fungal plasma membrane, $\times 88000$. f from [16] 

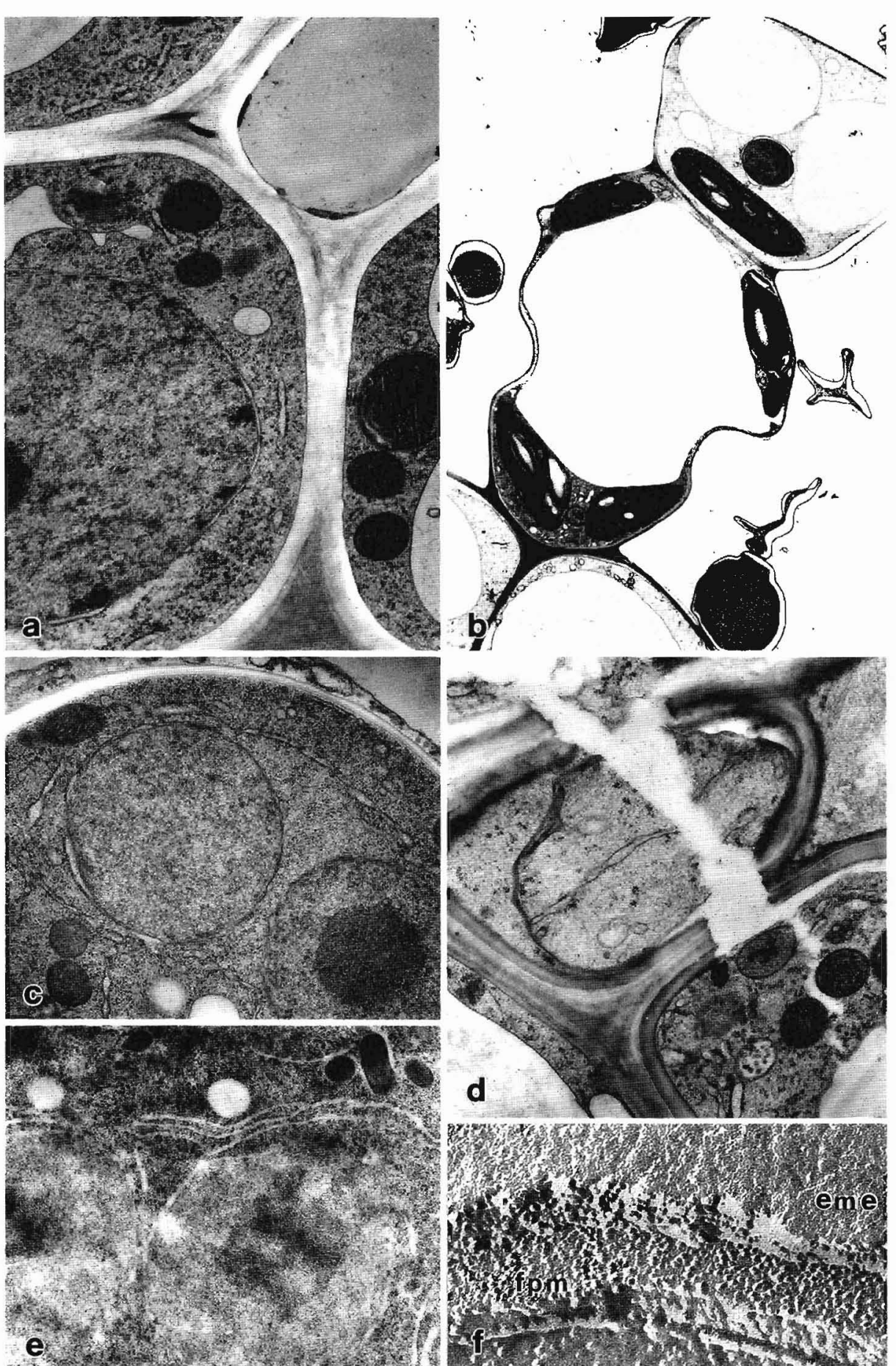

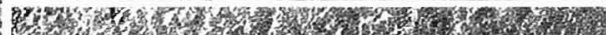
3. P.

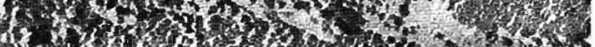

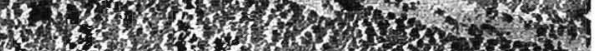

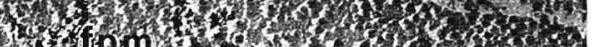

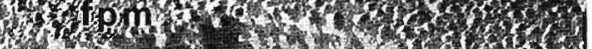

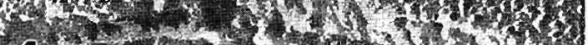
C 
(U. vicicae-fabae) in broad beans (Exp. 12), and brown rust (P. recondita) is wheat (Exp. 15).

As an alternative to methanol, we used 1-hexadecene for infiltration as a nonpenetrating agent that improves the contact between the metal of the specimen chamber and the sample [34]. Results with infected broad bean leaves (Exp. 8) or infected wheat leaves (Exp. 12) showed that nearly all intercellular hyphae and haustoria (Fig. 4c) were well preserved. In only 10-30\% of the cells of the leaf parenchyma, the cytoplasm was conveniently fixed except that prominent cracks were frequent (Fig. 4d). The vacuolar content of the leaf parenchyma had disintegrated into small bits and pieces.

Our results show that bean, broad bean, or wheat leaves cannot be cryofixed uniformly after infiltration with water or buffer only. Well preserved areas within the leaf tissue were quite small and mainly restricted to the vascular bundles. Sporogenous hyphae of the corresponding rusts were always well preserved. Infiltration with 1-hexadecene improved the situation considerably and should be used if a medium is needed that does not penetrate the cells. However, with our plants, we did not obtain the excellent results realized with apple leaves by Studer et al. [34]. For practical reasons, we recommend infiltration with methanol because it results in overall good fixation with well-preserved fine structure. This makes a survey of an infected leaf with the different developmental stages of a fungus much easier. However, although methanol appears to cause no major structural alterations, we are well aware that it may influence cell physiology. This remains an important disadvantage. However, methanol exhibited excellent cryoprotective properties for some algae [26] and surprisingly even $10 \%$ of this additive has been "nontoxic" ( $\geqq 75 \%$ survival after $15 \mathrm{~min}$ at $20^{\circ} \mathrm{C}$ ).

\section{Freeze-Substitution and Embedding}

The samples were either freeze-substituted in anhydrous acetone with $4 \% \mathrm{OsO}_{4}$ and embedded in Epon-Araldite [35] or freeze substituted in dried acetone alone for 3 days at $183 \mathrm{~K}$ and subsequently embedded in Lowicryl $\mathrm{K} 11 \mathrm{M}$ at $223 \mathrm{~K}\left(-50^{\circ} \mathrm{C}\right)$ as recommended by the producer. Material embedded in Lowicryl K $11 \mathrm{M}$ (Fig. 4e) was difficult to cut because sections tended to disintegrate in the water bath of the microtome knife and difficult to stain. Good contrast was obtained when the routine protocol for poststaining treatment with $3 \%$ uranylacetate for $30 \mathrm{~min}$ and lead citrate for $3 \mathrm{~min}$ was preceded by $2 \% \mathrm{OSO}_{4}$ in water for $10 \mathrm{~min}$.

\section{A Re-Evaluation of the Haustorial Host-Parasite Interface}

An important element in biotrophic relationships are fungal haustoria (Harder and Chong, Chap. 18, this Vol). A number of uncertainties regarding the fine structure of haustoria have remained because of problems associated with chemical fixation. Osmotic shock during fixation tends to separate the zone between host and parasite 


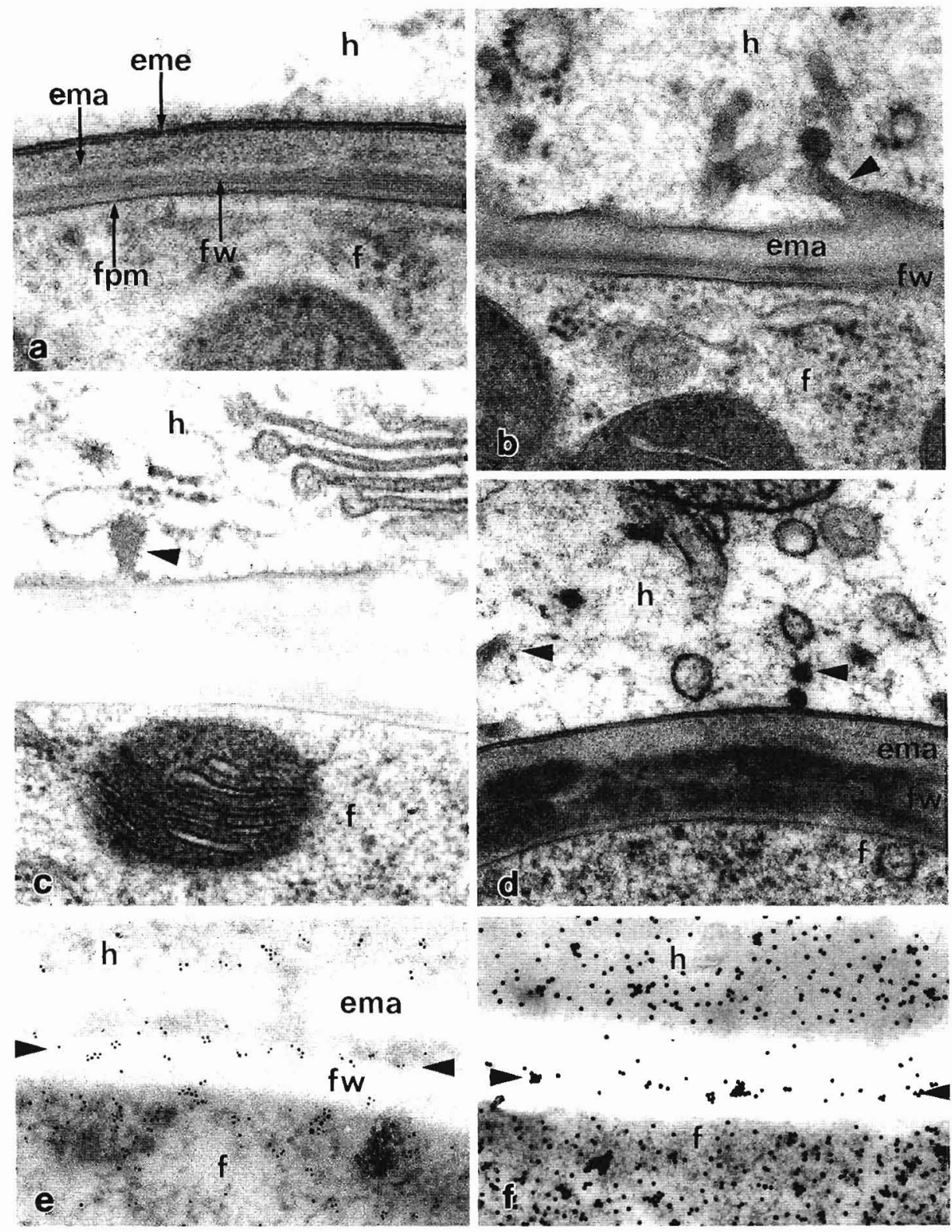

Fig. 5. The host-parasite interface of a $U$. appendiculatus and $P h$. vulgaris, processed as indicated for experiment $6, \times 41600$. b $P$. striiformis and T. aestivum; arrow extensions of the ema into the host cell protoplasts, exp. $16, \times 64300$. $P$. recondita and T. aestivum; arrow head "coated" pit, and fringe of material on the eme, exp. $15, \times 66400$. d U.fabae and V.faba, exp. $11, \mathrm{~K} 11 \mathrm{M}$ embedded, Con A-gold labeled; arrow heads indicate zone between ema and fw, $\times 64000$. f $U$. fabae and $V$. faba, exp. 11, K $11 \mathrm{M}$ embedded, PNA-gold labeled; arrow heads indicate zone between ema and $\mathrm{fw}, \times 54000$. ema extrahaustorial matrix; eme extrahaustorial membrane; $f$ fungus; $f p m$ fungal plasma membrane; $f w$ fungal wall; $h$ host plant 
[1]. The plasmamembranes of both organisms are quite undulated, possibly because membrane configurations around the fungal haustorium change during the long fixation period. Cryofixation has considerably improved structural preservation of haustoria [16]. Therefore, we compared several rust fungi for special features at their intercellular contact zone: The interface between the bean rust ( $U$. appendiculatus) haustoria and the host cell protoplasts (Figs. $4 \mathrm{f}$ and $5 \mathrm{a}$ ) may be said to extend from the "coated" extrahaustorial membrane (eme) to the fungal plasmamembrane (fpm), with the extrahaustorial matrix (ema) and the haustorial cell wall ( $\mathrm{fw}$ ) intervening between these two membranes (Fig. 5a). A freeze etch replica of the fpm reveals numerous intramembrane particles, whereas no such particles occur on the eme (Fig. 4f).

The extrahaustorial membrane around haustoria of $P$. striiformis is characterized by large tubular extensions reaching into the host cytoplasm (Fig. 5b). The extensions are in close contact, but apparently not continuous with the rough endoplasmatic reticulum of the host plant (Fig. 5b).

The extrahaustorial membrane that borders $P$. recondita haustoria is surrounded by "coated" vesicles, very often in contact with the "coated" extrahaustorial membrane. These vesicles were often in the neighborhood of dictyosomes (Fig. 5c).

The extrahaustorial membrane around haustoria of $U$. viciae fabae is surrounded by small "coated" tubules; the haustorial wall ( $\mathrm{fw}$ ) has uneven staining properties (Fig. $5 \mathrm{~d}$ ).

A molecular characterization of the haustorial host-parasite interface was obtained with lectins. Sections from tissue without chemical fixation embedded in Lowicryl K $11 \mathrm{M}$ were incubated with the gold-labeled lectin Concanavalin A (Con A-Gold) (Fig. 5e) and that of Arachis hypogea (PNA-Gold) (Fig. 5f) as described by Rohringer et al. [30] and Harder et al. [8]. A quite dense labeling with both lectins was observed over the cytoplasm of the host plant, Vicia faba and the parasite $U$. viciae-fabae. It is interesting that the contact zone between the extrahaustorial matrix and the fungal wall binds these two lectins (arrows, Fig. 5e, f).

These results need to be extended, and haustoria of different age should be compared to elucidate the development of the host-parasite interface during haustorium formation with these new techniques. It becomes evident already after these preliminary studies, that the extensions of the eme first described by Harder [7] and Chong and Harder [2] around haustoria of $P$. coronata avenae, with conventional techniques, exhibit typical conformations for each rust fungus [9] and may be used to differentiate rust fungi.

\section{Conclusions}

Our results have shown that the ultrastructure of fungal infections within leaf tissue can be studied using physical fixation by hpf. There is no evidence of major damage induced by the application of the high pressure if the tissue is properly pretreated. The samples may be studied after freeze fracturing or after freeze substitution, which 
may or may not include chemical fixation. Samples may be embedded in the conventional expoxy resins or in low temperature acrylic resin. The results are superior to those obtained with conventional techniques. Therefore, it is useful to verify previous results, particularly membrane contact zones or secretion events [22]. Furthermore, hpf combined with low temperature embedding is highly qualified for cytochemical studies.

However, some problems remain. The different components of the leaf and the fungus have different freezing qualities. Therefore, the samples should be as thin as possible. Infiltration of the intercellular space with water is not sufficient. Results were improved by infiltration with 1-hexadecene, but the best results for overall evaluation of leaf tissue were obtained by cryoprotection with methanol.

Acknowledgements. We thank Thomas Schmitz and Annette Klink for excellent technical assistance, D. E. Harder, Winnipeg, G. Knoll and H. Plattner, Konstanz, for reviewing the manuscript and Jutta Schlepper-Schäfer for a generous gift of PNA-Gold. The Deutsche Forschungsgemeinschaft helped with grants (Me 523/12, Me 523/13).

\section{References}

1. Allen FHE, Coffey MD, Health MC (1979) Plasmolysis of rusted flax: a fine-structural study of the host-pathogen interface. Can J Bot 57: 1528-1533

2. Chong J, Harder DE (1982) Ultrastructure of haustorium development in Puccinia coronata avenae: some host responses. Phytopathology 72:1527-1533

3. Craig S, Gilkey JC, Staehelin LA (1987) Improved specimen support cups and auxiliary devices for the Balzers high pressure freezing apparatus. J Microsc 148: $103-106$

4. Craig S, Staehelin LA (1988) High pressure freezing of intact plant tissues. Evaluation and characterization of novel features of the endoplasmic reticulum and associated membrane systems. Eur J Cell Biol 46: 80-93

5. Dahmen H, Hobot JA (1986) Ultrastructural analysis of Erysiphe graminis haustoria and subcuticular stroma of Venturia inaequalis using cryosubstitution. Protoplasma 131: $92-102$

6. Gilkey JC, Staehelin LA (1986) Advances in ultrarapid freezing for the preservation of cellular ultrastructure. J Electron Microsc Tech 3: 177-210

7. Harder DE (1978) Comparative ultrastructure of the haustoria in uredial and pycnial infections of Puccinia coronata avenae. Can J Bot 56: 214-224

8. Harder DE, Chong J, Rohringer R, Mendgen K, Schneider A, Welter K, Knauf G (1989) Ultrastructure and cytochemistry of extramural substances associated with intercellular hyphae of several rust fungi. Can J Bot 67: 2043-2051

9. Heath MC, Bonde MR (1983) Ultrastructural observation of the rust fungus Physopella zeae in Zea mays. Can J Bot 61: 2231-2242

10. Hippe $\mathrm{S}$ (1985) Ultrastructure of haustoria of Erysiphe graminis F. sp. hordei preserved by freeze-substitution. Protoplasma 129: 52-61

11. Hoch HC, Staples RC (1983) Ultrastructural organization of the non-differentiated uredospore germling of Uromyces phaseoli variety typica. Mycologia 75: 795-824

12. Howard RJ, Aist JR (1979) Hyphal tip cell ultrastructure of the fungus Fusarium: improved preservation by freeze-substitution. J Ultrastruct Res 66: 224--234

13. Howard RJ, O’Donnel] KL (1987) Methodological review. Freeze substitution of fungi for cytological analysis. Exp Mycol 11:250-269

14. Kaeser W, Koyro H-W, Moor H (1989) Cryofixation of plant tissues without pretreatment. J Microsc 154: 279-288

15. Knauf $G$, Mendgen $K$ (1988) Secretion systems and membrane-associated structures in rust fungi after high pressure freezing and freeze-fracturing. Biol Cell 64: 363-370 
16. Knauf G, Welter K, Müller M, Mendgen K (1989) The haustorial host-parasite interface in rust-infected bean leaves after high-pressure freezing. Physiol Mol Plant Pathol 34: $519-530$

17. Knoll G, Verkleij AJ, Plattner H (1987) Cryofixation of dynamic processes in cells and organelles. In: Steinbrecht RA, Zierold K (eds) Cryotechniques in biological electron microscopy. Springer, Berlin Heidelberg New York Tokyo, pp 258-271

18. Littlefield LJ, Heath MC (1979) Ultrastructure of rust fungi. Academic Press, New York

19. MC Cully ME, Canny MJ (1985) The stabilization of labile configurations of plant cytoplasm by freeze-substitution. J Microsc 139:27-33

20. McDonald AG (1984) The effects of pressure on the molecular structure and physiological functions of cell membranes. Philos Trans R Soc, Lond, Ser B 304: 47-68

21. Mendgen K, Schneider A, Sterk M, Fink W (1988) The differentiation of infection structures as a result of recognition events between some biotrophic parasites and their hosts. J Phytopathol 123: 259-272

22. Mendgen K (1989) Secretion in the parasitic phase of rust fungi. In: Lugtenberg B (ed) Molecular signals in microbe-plant symbiotic and pathogenic systems. NATO Series, Springer, Berlin Heidelberg New York Tokyo, pp 281-288

23. Mersey B, McCully ME (1978) Monitoring the course of fixation of plant cells. J Microsc 114: $49-76$

24. Mims CW, Richardson EA, Timberlake WE (1988) Ultrastructural analysis of conidiophore development in the fungus Aspergillus nidulans using freeze-substitution. Protoplasma 144: $132-141$

25. Moor H (1987) Theory and practice of high pressure freezing. In: Steinbrecht RA, Zierold $\mathrm{K}$ (eds) Cryotechniques in biological electron microscopy. Springer, Berlin Heidlberg New York Tokyo, pp 175-191

26. Morris GJ, Canning CE (1978) The cryopreservation of Euglena gracilis. J Gen Microbiol 108: $27-31$

27. Müller H, Moor $H$ (1984) Cryofixation of thick specimens by high pressure freezing. In: Revel J-P, Barnard T, Hagis GH (eds) The science of biological specimen preparation. SEM, AMF O'Hare, IL 60666, pp 131-138

28. Plattner H, Bachmann L (1982) Cryofixation: a tool in biological ultrastructural research. Int Rev Cytol 79: 237-304

29. Robards AW, Sleytr UB (1985) Low temperature methods in biological electron microscopy. In: Glauert AM (ed) Practical methods in electron microscopy, Vol 10. Elsevier, Amsterdam

30. Rohringer R, Chong J, Gillespie R, Harder DE (1989) Gold-conjugated arabinogalactanprotein and other lectins as ultrastructural probes for the wheat/stem rust complex. Histochemistry 91: 383-393

31. Sitte H (1979) Cryofixation of biological material without pretreatment. A review. Mikroskopie (Wien) 35: 121-131

32. Sitte H, Edelmann L, Neumann K (1987) Cryofixation without pretreatment at ambient pressure. In: Steinbrecht RA, Zierold K (eds) Cryotechniques in biological electron microscopy. Springer, Berlin Heidelberg New York Tokyo, pp 87-113

33. Steinbrecht RA, Zierold K (1987) Cryotechniques in biological electron microscopy. Springer, Berlin Heidelberg New York Tokyo

34. Studer D, Michel M, Müller M (1989) High pressure freezing comes of age. Scanning Microscopy, Suppl 3: 253-269

35. Welter K, Müller M, Mendgen K (1988) The hyphae of Uromyces appendiculatus within the leaf tissue after high pressure freezing and freeze substitution. Protoplasma 147: $91-$ 99

36. Draznin B, Dahl R, Sherman N, Sussman KE, Staehelin A (1988) Exocytosis in normal anterior pituitary cells. J Clin Invest 81: 1042-1050

37. Dahl R, Staehelin A (1989) High-pressure freezing for the preservation of biological structure: Theorie and practice. J Electr Micr Techn 13: 165-174 